\title{
SAFETY AND EFFICACY OF THREE TREATMENT REGIMENS OF R-CHOP, E-CHOP, AND R-CHOEP IN NON-HODGKIN LYMPHOMA CANCER PATIENTS
}

\author{
AYAZ AHMAD ${ }^{1 *}$, MOHAMMAD DAUD ALI ${ }^{1}$, SANA ALMAHMOUD ${ }^{2,3}$ \\ ${ }^{1}$ Department of Pharmacy, Mohammad Almana College of Health Sciences, Abdulrazaq Bin Hammam Street, As Safa, Dammam 34222, \\ Saudi Arabia. ${ }^{2}$ Department of Nursing, Mohammad Almana College of Health Sciences, Abdulrazaq Bin Hammam Street, As Safa, Dammam \\ 34222, Saudi Arabia. ${ }^{3}$ Department of Nursing Education, College of Nursing, Imam Abdulrahman Bin Faisal University, King Faisal Road, \\ Dammam 34212, Saudi Arabia. Email: 1980ayaz@gmail.com \\ Received: 19 December 2017, Revised and Accepted: 07 March 2018
}

\section{ABSTRACT}

Objective: This study was designed to investigate safety, efficacy of different regimens such as R-CHOP, E-CHOP, and R-CHOEP used in the treatment of in non-Hodgkin lymphoma (NHL) cancer patients.

Methods: Available and required data of 64 NHL cancer patients were collected. Data were related to demography of patients, name of the drug, dose, route, frequency, duration of therapy, and investigational reports.

Results: This study showed some variation and similarities in different regimens. Arm-A (R-CHOP) and Arm-B (E-CHOP) showed similar result for Eastern Cooperative Oncology Group (ECOG) score 2 but showed different result of ECOG score 0 and 1 . High percentage of patient was taken in Arm-A and Arm-B as compared to Arm-C (R-CHOEP) for ECOG score 2. Surprisingly, it was found that very few percentages of patients showing progressive disease during R-CHOEP as compared to R-CHOP, E-CHOP therapy.

Conclusion: From this study, it was concluded that Arm-C (R-CHOEP) showed better result in comparison of Arm-A (R-CHOP) and Arm-B (E-CHOP). As far as toxicity is concern, early detection and personalized management may improve clinical outcome and tolerance.

Keywords: Non-hodgkin lymphoma, Eastern Cooperative Oncology Group score, Prognostic index, Response evaluation criteria in solid tumors criteria. (C) 2018 The Authors. Published by Innovare Academic Sciences Pvt Ltd. This is an open access article under the CC BY license (http://creativecommons. org/licenses/by/4. 0/) DOI: http://dx.doi.org/10.22159/ajpcr.2018.v11i6.24345

\section{INTRODUCTION}

Lymphoma is the type cancer where tumors begin in infection-fighting cells of the immune system, called lymphocytes [1]. There are many subtypes of lymphomas [2]. The Hodgkin lymphomas (HLs) and the non-HL (NHLs) comes under major category of lymphoma $[3,4]$. About $90 \%$ of lymphomas are non-HLs [5,6]. NHL does not involve ReedSternberg cells. There are more than 61 different types of NHL, some of which are more frequent than others [7]. Autoimmune diseases, HIV/ AIDS, infection with human T-lymphotropic virus, immunosuppressant medications increase the risk of NHLs [2]. Eating large amounts of red meat may also increase the risk lymphoma [8-10].

There were about 19.7 cases of NHL per 100,000 adults per year, 6.3 deaths per 100,000 adults per year in the USA [11].

In KSA, NHL accounting for 703 cases and $7.1 \%$ of all newly diagnosed cancers in the year 2010. It affected 407 (57.9\%) males and 296 (42.1\%) females with a male-to-female ratio of $138: 100$. The median age was 49 years among males (range $0-101$ years) and 55 years among females (range 2-92 years) [12].

R-CHOP regimen has been the first-line chemotherapy for NHL patients. CHOP is also prescribed as chemotherapy regimen for NHL in some clinical settings [13]. However, the efficacy and safety of these three regimens (R-CHOP, E-CHOP, and R-CHOEP) have not been head-to-head compared in a randomized study. The aim of this study is to compare the efficacy and safety of R-CHOP, E-CHOP, and R-CHOEP in previously untreated NHL patients.

\section{METHODS}

Research was carried out in compliance with the Helsinki Declaration with completion of certificate (Certificate number: 2086281) from
National Institute of Health office of extramural research protecting human research participants. The consent was about not to disclose the name of patient and data collected from treatment chart, patient's case note, and laboratory investigational reports, and data that will be used only for publication purpose.

\section{Patient enrolment}

Patient was taken (Fig. 1) in consideration for this study on the basis of following inclusion and exclusion criteria.

\section{Inclusion criteria}

- Positive diffuse large B-cell lymphoma

- Histological or cytological confirmed or metastatic carcinoma of NHL

- Ann Arbor stage I IV

- Eastern Cooperative Oncology Group (ECOG) physical score of 0 2

- Have at least one clinically measurable lesion: $\geq 2 \mathrm{~cm}$ under physical examination

- Life expectancy of $\geq 3$ months

- $\quad$ Age between 18 and 70 years

- Patient at least completed two cycles of chemotherapy

- Both sexes (male and female)

- SGOT, SGPT, and total bilirubin $\leq 2 \times$ upper limit of normal (ULN)

- Glomerular filtration rate (MDRD method) $\geq 30 \mathrm{~mL} / \mathrm{min}$

- No evidence of HIV and active hepatitis B or C virus

- Cardiac function of Class I-II in New York Heart Association classification.

Exclusion criteria

- Indolent lymphoma patients

- Serum Epstein-Barr virus DNA $\geq 1000$ copies/mL

- Double-hit lymphoma confirmed by fluorescence in situ hybridization (FISH)

- $\quad$ Primary mediastinal B-cell lymphoma

- Central nervous system problem. 


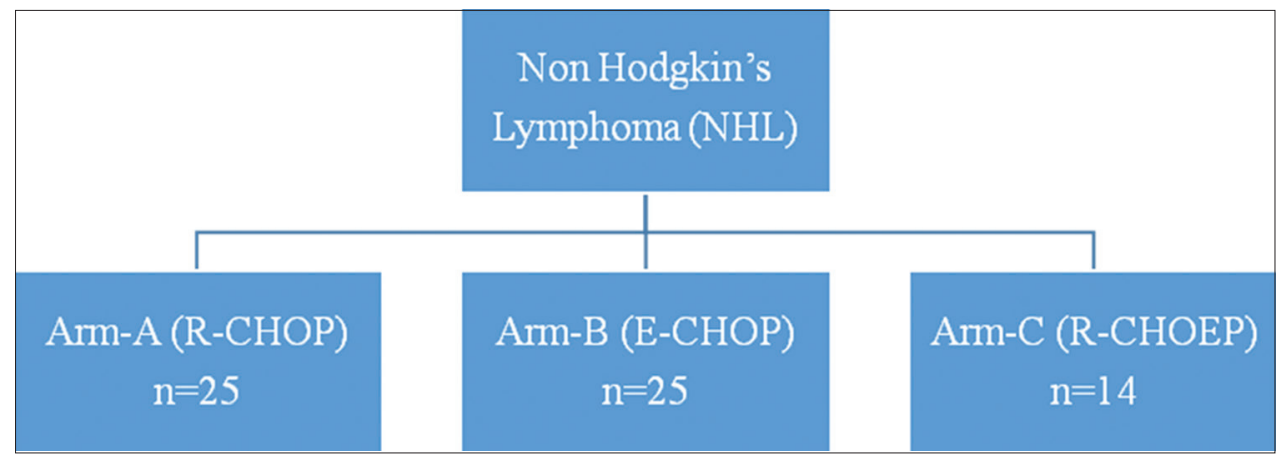

Fig 1: Distribution of different regimen ( $n$ is the number of patient)

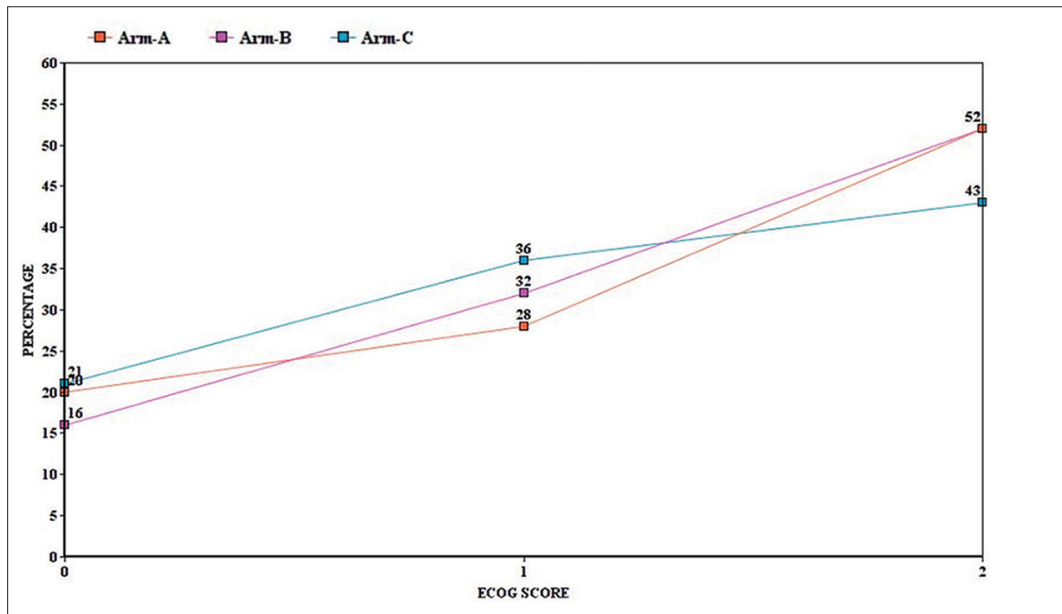

Fig 2: Eastern Cooperative Oncology Group Score among all three regimens

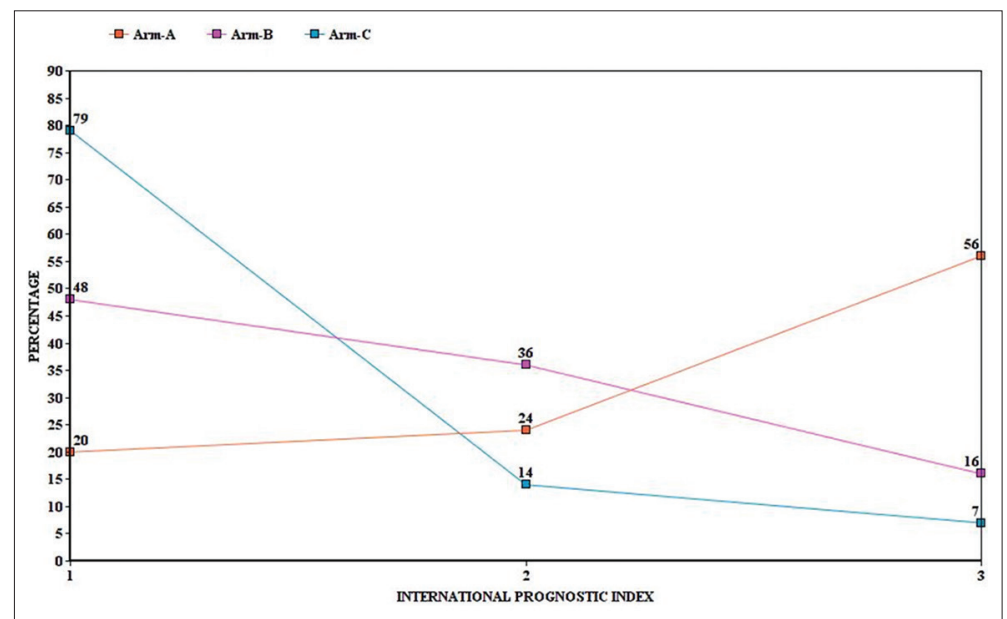

Fig 3: Prognostic index among all three regimens

Table 1: Dosing schedule of R-CHOP regimen

\begin{tabular}{llll}
\hline Drug & Dose & Mode & Days \\
\hline Rituximab & $375 \mathrm{mg} / \mathrm{m}^{2}$ & IV & Day 1 \\
Prednisolone & $60 \mathrm{mg} / \mathrm{m}^{2}$ & PO & Days 1-5 \\
Oncovin & $0.4 \mathrm{mg} / \mathrm{m}^{2}$ & IV & Days 1-4 \\
Cyclophosphamide & $750 \mathrm{mg} / \mathrm{m}^{2}$ & IV & Day 5 \\
Hydroxydaunorubicin & $10 \mathrm{mg} / \mathrm{m}^{2}$ & IV & Days 1-4 \\
\hline
\end{tabular}

\section{Collection of data}

Available and required data of 64 NHL cancer patients were collected. Data were related to demography of patients, name of the drug, dose, route, frequency, duration of therapy, and investigational reports. Drug regimens are summarized in Tables 1-3.

\section{Evaluation of toxicity}

All hematological, non-hematological toxicity were evaluated as per Common Terminology Criteria for Adverse Events v4.0.

\section{Statistical analysis}

The data were collected to compare the safety, efficacy, and toxicity between Arm-A, Arm-B, and Arm-C. Values were expressed as percentages. Comparison of the mean values within the group was done using t-test. $\mathrm{p}<0.05$ was considered to indicate statistical significance. Statistical analysis was performed by SAS software version 9.4 . 
Table 2: Dosing schedule of EPOCH regimen

\begin{tabular}{llll}
\hline Drug & Dose & Mode & Days \\
\hline Etoposide & $50 \mathrm{mg} / \mathrm{m}^{2}$ & IV & Days 1-4 \\
Prednisolone & $60 \mathrm{mg} / \mathrm{m}^{2}$ & PO & Days 1-5 \\
Oncovin & $0.4 \mathrm{mg} / \mathrm{m}^{2}$ & IV & Days 1-4 \\
Cyclophosphamide & $750 \mathrm{mg} / \mathrm{m}^{2}$ & IV & Day 5 \\
Hydroxydaunorubicin & $10 \mathrm{mg} / \mathrm{m}^{2}$ & IV & Days 1-4 \\
\hline
\end{tabular}

Table 3: Dosing schedule of R-EPOCH regimen

\begin{tabular}{llll}
\hline Drug & Dose & Mode & Days \\
\hline Rituximab & $375 \mathrm{mg} / \mathrm{m}^{2}$ & IV & Day 1 \\
Etoposide & $50 \mathrm{mg} / \mathrm{m}^{2}$ & IV & Days 1-4 \\
Prednisolone & $60 \mathrm{mg} / \mathrm{m}^{2}$ & PO & Days 1-5 \\
Oncovin & $0.4 \mathrm{mg} / \mathrm{m}^{2}$ & IV & Days 1-4 \\
Cyclophosphamide & $750 \mathrm{mg} / \mathrm{m}^{2}$ & IV & Day 5 \\
Hydroxydaunorubicin & $10 \mathrm{mg} / \mathrm{m}^{2}$ & IV & Days 1-4 \\
\hline
\end{tabular}

\section{RESULTS}

A total of 64 patients with NHL treated with first-line chemotherapy were identified. Patient was classified in different clinical staging and found in Grade II and IV. Patient showed different ECOG score. Maximum number of patient was showing ECOG score 2. In Arm-A, maximum number of patient showed international prognostic index 3, but Arm-B and Arm-C showed international prognostic index 0-1. Other biological and diagnostical parameters were also taken into account. All the three groups were examined for response evaluation criteria in solid tumors (RECIST) to know the efficacy of different regimen. Patient's characteristics are summarized in Table 4.

\section{DISCUSSION}

In 1997, rituximab was approved for medical use [14]. According to the WHO, it is the most effective and safe medication for the treatment of lymphoma $[15,16]$. It is used to treat NHL and predominantly different subtypes of Hodgkin's lymphoma [17]. In the USA, etoposide was

Table 4: Patient's characteristics of all three regimens NHL patients

\begin{tabular}{llll}
\hline Characteristic & $\mathbf{n}(\%)$ - Arm-A & $\mathbf{n}(\%)$ - Arm-B & n (\%) - Arm-C \\
\hline $\begin{array}{l}\text { Middle age (range) } \\
\text { Gender }\end{array}$ & 43 years old (18-70) & 46 years old (18-70) & 47 years old (18-70) \\
$\quad$ Male & $20(80)$ & $19(76)$ & $10(71)$ \\
$\quad$ Female & $5(20)$ & $6(24)$ & $4(29)$ \\
Clinical staging & & & $6(43)$ \\
$\quad$ Grade II & $11(44)$ & $10(40)$ & $8(57)$ \\
$\quad$ Grade IV & $14(56)$ & $15(60)$ & $3(21)$ \\
ECOG score & $5(20)$ & $4(16)$ & $5(36)$ \\
0 & $7(28)$ & $8(32)$ & $6(43)$ \\
1 & $13(52)$ & $13(52)$ & $11(79)$ \\
2 & $5(20)$ & $12(48)$ & $2(14)$ \\
International prognostic index & $6(24)$ & $9(36)$ & $1(7)$ \\
$0-1$ & $14(56)$ & $4(16)$ & \\
2 & $15(60)$ & $13(52)$ & $5(36)$ \\
3 & $20(80)$ & $10(40)$ & $6(43)$ \\
Others & $18(72)$ & $13(52)$ & $4(29)$ \\
Weight lose & $22(88)$ & $15(50)$ & $3(21)$ \\
Neutropenic fever & & & \\
Pneumonia & $2(8)$ & $4(16)$ & $3(21)$ \\
LDH (>240 IU/L) & $13(52)$ & $18(72)$ & $10(71)$ \\
Efficacy parameter: RECIST criteria & $7(28)$ & $2(8)$ & $2(14)$ \\
CR & $3(12)$ & $1(4)$ & $0(0)$ \\
PR & SD & &
\end{tabular}

RECIST: Response evaluation criteria in solid tumors, CR: Complete response, PR: Partial response, SD: Stable disease, PD: Progressive disease, ECOG: Eastern Cooperative Oncology Group

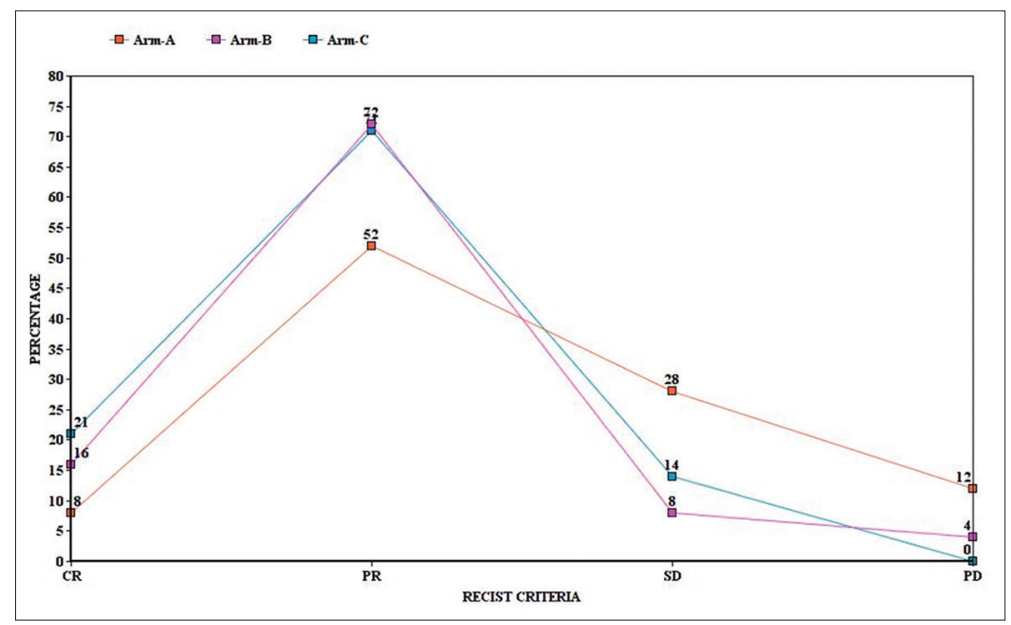

Fig 4: Response evaluation criteria in solid tumors criteria of all three regimens 
approved in 1983 [18]. Besides that, it is also used before bone marrow or blood stem cell transplant [19].

For this study, similar number of patients was found in Arm-A and Arm-B, but there was less number of patients in Arm-C. This study showed some variation and similarities in different regimen. Arm-A (R-CHOP) and Arm-B (E-CHOP) showed similar result for ECOG score 2 but showed different result of ECOG score 0 and 1 . High percentage of patient was taken in Arm-A and Arm-B as compared to Arm-C for ECOG score 2 (Fig. 2).

For prognostic index, high percentage of patients was found in low risk for Arm-C as compared to Arm-B and Arm-A. Similarly, there was low percentage of patients in case of Arm-C as compared to Arm-B and Arm-A (Fig. 3).

Different regimen was compared for RECIST, and it was found comparative result with Arm-C. There was more percentage of patients showing complete response with Arm-C as compared to Arm-A and Arm-B. Surprisingly, it was found that very few percentages of patients showing progressive disease during R-CHOEP as compared to R-CHOP, E-CHOP therapy (Fig. 4).

\section{CONCLUSION}

From this study, it was concluded that Arm-C (R-CHOEP) showing better efficacy as compared to Arm-A (R-CHOP) and Arm-B (E-CHOP). An early detection of toxicity and personalized management may improve clinical outcome and tolerance. However, these results need additional information regarding prognostic factors and patients with advanced NHL should be validated in prospective studies.

\section{ACKNOWLEDGMENT}

We would like to thank Dr. Aysha Almana, Dr. EmadAlbaba, Mrs. Amal Kolghassi, and Dr. Yousif Amin, MACHS, for supporting and making successful completion of this study.

\section{CONFLICTS OF INTEREST}

The authors declare that there are no conflicts of interest.

\section{REFERENCES}

1. Elizabeth JT. Dorland's Illustrated Medical Dictionary. $29^{\text {th }}$ ed. Philadelphia, PA: Saunders; 2000. p. 1038.

2. National Cancer Institute. General Information About Adult Hodgkin Lymphoma. Bethesda, MD: National Cancer Institute; 2014.
3. National Cancer Institute. General Information about Adult nonHodgkin Lymphoma. Bethesda, MD: National Cancer Institute; 2014. Available from: https://www.cancer.gov/types/lymphoma/patient/ adult-nhl-treatment-pdq. [Last retrieved on 2014 Jun20].

4. Bardia A. Johns Hopkins Patients' Guide to Lymphoma. Burlington, Massachusetts, United States: Jones and Bartlett Learning; 2010 p. 6.

5. Available from: https://www.lls.org/sites/default/files/file assets/ lymphomaguide.pdf.

6. Available from: http://www.publications.iarc.fr/Non-Series-Publications/ World-Cancer-Reports/World-Cancer-Report-2014.

7. Hande KR. Etoposide: Four decades of development of a topoisomerase II inhibitor. Eur J Cancer 1998;34:1514-21.

8. Antony A, Joel JJ, Shetty J, Umar NF. Identification and analysis of adverse drug reactions associated with cancer chemotherapy in hospitalized patients. Int J Pharm Pharm Sci 2016;8:448-51.

9. Yang L, Dong J, Jiang S, Shi W, Xu X, Huang H, et al. Red and processed meat consumption increases risk for non-hodgkin lymphoma: A PRISMA-compliant meta-analysis of observational studies. Medicine (Baltimore) 2015;94:e1729.

10. Solimini AG, Lombardi AM, Palazzo C, De Giusti M. Meat intake and non-hodgkin lymphoma: A meta-analysis of observational studies. Cancer Causes Control 2016;27:595-606.

11. Maeda E, Akahane M, Kiryu S, Kato N, Yoshikawa T, Hayashi N, et al. Spectrum of epstein-barr virus-related diseases: A pictorial review. Jpn J Radiol 2009;27:4-19.

12. Available from: https://www.seer.cancer.gov/statfacts/html/nhl.html

13. "Etoposide". The American Society of Health-System Pharmacists. Available from: http://www.bccancer.bc.ca/drug-database-site/ Drug\%20Index/Etoposide_monograph_1Mar2017.pdf. [Last retrieved on 2016 Dec 08]

14. Gupta M, Dahiya J, Marwaha RK, Dureja H.Therapies in Cancer Treatment: An Overview. Int J Pharm Pharm Sci 2015;7:1-9.

15. Bosch X, Ramos C, Manuel K, Munther A. Drugs Targeting B-Cells in Autoimmune Diseases. Berlin/Heidelberg, Germany: Springer Science \& Business Media; 2013. p. 1-4.

16. WHO. WHO Model Formulary 2008. Geneva: World Health Organization; 2009. p. 227. Available from: http://apps.who.int/iris/ handle/10665/44053. [Last retrieved on 2016 Dec 08].

17. Bosch X, Ramos C, Manuel K, Munther A. Drugs Targeting B-Cells in Autoimmune Diseases. Berlin/Heidelberg, Germany: Springer Science \& Business Media; 2013. p. 1-4.

18. WHO. Model List of Essential Medicines. 19 $9^{\text {th }}$ List. Geneva: World Health Organization; 2015. Available from: http://www.who.int/ medicines/publications/essentialmedicines/en/. [Last retrieved on 2016 Dec 08].

19. Saini KS, Azim HA Jr., Cocorocchio E, Vanazzi A, Saini ML, Raviele PR, et al. Rituximab in Hodgkin lymphoma: Is the target always a hit? Cancer Treat Rev 2011;37:385-90.s 